\title{
Studi Analisis Perbandingan Rugi Daya Pada Titik Sambung Pierching Connector Dengan Line Tap Connector Pada Jaringan Tegangan Rendah
}

\author{
Ahmad Syaifuddin $\mathrm{F}^{1}$ Arief Budi Laksono ${ }^{2}$, Suharijanto ${ }^{3}$ \\ ${ }^{1)}$ Program Studi Teknik Elektro Universitas Islam Lamongan \\ ${ }^{2,3)}$ Dosen Fakultas Teknik Prodi Teknik Elektro Universitas Islam Lamongan \\ email : adioferdian@gmail.com, arifbudila@unisla.ac.id, suharjanto@unisla.ac.id
}

\begin{abstract}
Distribution system is divided into primary and secondary distribution networks. The primary distribution network is the network of the substation to the distribution, while the secondary distribution is the channel network from the substation transformer is distributed to the consumer or the load. Primary distribution network is better known as medium voltage network (JTM 20kV) while secondary distribution is low voltage network (JTR 220 / 380V). The distribution network is part of the power system closest to the customer or the load compared to the transmission network.

At this time PT. PLN (Persero) experiencing power loss that occurs at the point of connection of low voltage on the use of pierching connector. This study is to analyze the calculation of loss of power at low voltage network (JTR) by doing comparison of measurement between input with output at connection point of pierching connector with line tap connector. For conditions required evaluation and analysis for replanning that takes into account the planning criteria such as voltage drop and take into account the loss of power.
\end{abstract}

Keywords : distribution network, connector, measurement and losses

\section{ABSTRAK}

Pada sistem distribusi dibedakan atas jaringan distribusi primer dan sekunder. Jaringan distribus i primer adalah jaringan dari trafo gardu induk (GI) ke gardu distribusi, sedangkan distribusi sekunder adalah jaringan saluran dari trafo gardu ditribusi hingga konsumen atau beban. Jaringan distribus i primer lebih dikenal dengan jaringan tegangan menengah (JTM 20kV) sedangkan distribusi sekunder adalah jaringan tegangan rendah (JTR 220/380V). Jaringan distribusi merupakan bagian dari sistem tenaga listrik yang terdekat dengan pelanggan atau beban dibanding dengan jaringan transmisi.

Pada saat ini PT. PLN (Persero) mengalami rugi daya yang terjadi pada titik sambung jaringan tegangan rendah (JTR) pada penggunaan pierching connector. Penelitian ini adalah menganalisa perhitungan rugi daya pada jaringan tegangan rendah (JTR) dengan melakukan perbandingan pengukuran antara input dengan output pada titik sambung pierching connector dengan line tap connector. Dengan adanya kondisi tersebut diperlukan evaluasi dan analisa untuk perencanaan kembali yang memperhatikan kriteria-kriteria perencanaan seperti jatuh tegangan dan memperhitungkan rugi daya demi kelangsungan pelayanan listrik sehingga muncul optimasi pada jaringan yang dipakai.

Kata Kunci : sistem distribusi, JTR, connector, pengukuran, dan rugi daya

\section{Pendahuluan}

\section{Latar Belakang}

Tenaga listrik disalurkan ke masyarakat melalui jaringan distribusi. Oleh sebab itu jaringan distribusi merupakan bagian jaringan listrik yang paling dekat dengan masyarakat. Jaringan distribusi dikelompokkan menjadi dua, yaitu jaringan distribusi primer dan jaringan distribusi sekunder. Tegangan distribusi primer yang dipakai PLN adalah $20 \mathrm{kV}$. Tegangan pada jaringan distribusi primer, diturunkan oleh gardu distribusi menjadi jaringan distribusi sekunder atau tegangan rendah yang besarnya adalah $380 / 220 \mathrm{~V}$, dan disalurkan kembali melalui jaringan tegangan rendah kepada konsumen.

Rugi daya adalah suatu kondisi atau keadaan dimana jumlah daya yang disalurkan tidak sama dengan daya yang diterima pada sisi penerimaan. Terjadinya rugi-rugi daya ini dapat disebabkan oleh berbagai faktor, seperti jauhnya 
daerah penyaluran tenaga listrik dari sumber/suplai, voltage drop, Ketidakseimbangan beban, umur peralatan, diameter penghantar dan lain-lain.

Rugi daya menyeluruh tetapi hanya bisa diminimalkan (di reduksi). Loss situation di dalam jaringan distribusi tenaga listrik adalah suatu kondisi atau keadaan dimana suatu sistem distribusi di dalam pendistribusian tenaga listriknya mengalami rugi daya yang tinggi.

Rumusan masalah dari penelitian ini adalah :

a) Berapa hasil perbandingan pengukuran nilai input dan output pierching connector dengan line tap connector?

b) Berapa hasil perhitungan rugi energi daya listrik dalam satuan rupiah pada pierching connector?

c) Mengapa pemasangan pierching connector pada jaringan tegangan rendah nilai input dan output nya menghasilkan nilai tegangan yang tidak sama?

\section{Metode Pene litian \\ Waktu dan Lokasi Pene litian}

Waktu penelitian dimulai pada bulan Maret Mei 2017. Penelitian ini dilaksanakan di PT. PLN (Persero) Rayon Lamongan. Untuk lokasi penelitian di Ds. Balun Kec. Turi Lamongan.

\section{Jenis Penelitian}

Metode kuantitatif adalah penelitian yang menggunakan metode ilmiah/scientifik karena telah memenuhi kaidah-kaidah ilmiah yaitu konkrit/empiris, obyektif, terukur, rasional, dan sistematis, disebut metode kuantitatif karena penelitian berupa angka-angka dan analis is menggunakan statistik.

\section{Teknik Pengumpulan Data}

1) Observasi (pengamatan)

2) Wawancara

3) Dokumentasi

Metode Pengumpulan Data

1) Data Primer

2) Data Sekunder

\section{Metode Analis a Data}

Untuk menganalsis data perhitungan rugi daya, maka penulis melakukan pengukuran pada titik sambung jaringan tegangan rendah (JTR) input dan output connector, setelah itu data diolah oleh penulis untuk mencapai tujuan penelitian penulis dengan cara menggunakan metode:

1) Perhitungan daya aktif dalam satuan watt, untuk mengetahui arus total input dan output.

2) Perhitungan rugi daya, dengan cara mengurangi hasil input dengan output.

3) Perhitungan rugi energi daya listrik dalam satuan rupiah, untuk mengetahui nilai rupiah kerugian daya.

\section{Flowchart Pere ncanaan}

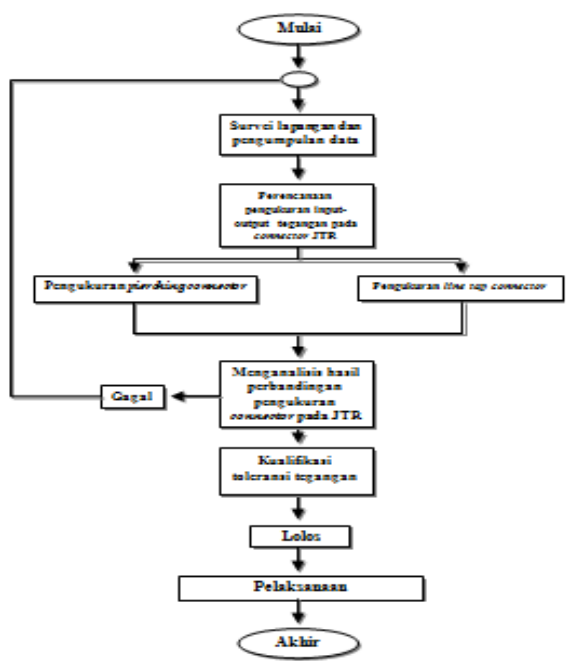

Gambar 1. Diagram alir pe ne litian

\section{Analis is Perencanaan Pengukuran Pierching Connector dengan Line Tap Connector}

Dalam melaksanakan program tugas akhir ini penulis menitik beratkan pada permasalahan perbandingan pengukuran pierching connector dengan line tap connector pada jaringan tegangan rendah (JTR). Penulis mengambil analisa ini di daerah Ds. Balun Kec. Turi Lamongan. Tanggal pelaksanaan 14 April 2014. Waktu 16.30 - 18.00 WIB.

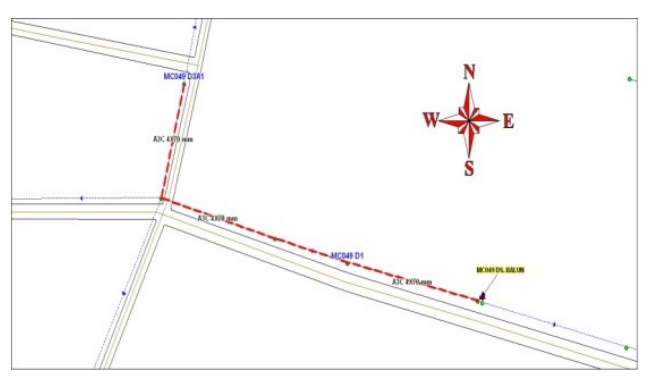

Gambar 2. Single Line JTR T. 049 Ds. Balun Kec. Turi Lamongan 
Dari hasil survei lapangan di daerah tersebut, penulis menemukan titik sambung kabel line JTR yang menggunakan pierching connector dengan line tap connector, maka penulis melakukan pengukuran dan mengambil hasil analisis tersebut. Pengukuran titik sambung jaringan tegangan rendah (JTR) dilakukan dengan cara mengukur nilai R-N, S-N dan T-N pada input dan output connector yang terpasang pada jaringan tegangan rendah (JTR).

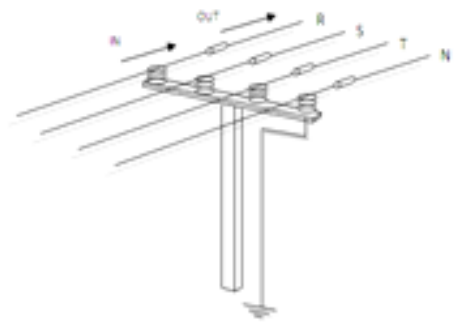

Gambar 3. Jaringan Tegangan Rendah (JTR)

Hasil Pengukuran GTT PT. PLN (Persero) Rayon Lamongan Pada T. 49

Hasil pengukuran GTT T. 49 pada box panel :

1. Tegangan dan nilai $\operatorname{Cos} \varphi$
$\mathrm{R}-\mathrm{N}: 239,6 \mathrm{~V}$
$\operatorname{Cos} \varphi \mathrm{R}: 0,9,3$
S-N : 241,4 V
$\operatorname{Cos} \varphi \mathrm{S}: 0,9,0$
$\mathrm{T}-\mathrm{N}: 239,5 \mathrm{~V}$
$\operatorname{Cos} \varphi \mathrm{T}: 0,9,3$

2. Beban Line Dalam Satuan Ampere dan nilai $\operatorname{Cos} \varphi$
$\mathrm{R}: 38,7 \mathrm{~A}$
$\operatorname{Cos} \varphi: 0,9$
$\mathrm{S}: 27,1 \mathrm{~A}$
$\operatorname{Cos} \varphi: 0,9$
$\mathrm{T}: 49,7 \mathrm{~A}$
$\operatorname{Cos} \varphi: 0,9$
$\mathrm{N}: 18,4 \mathrm{~A}$
$\operatorname{Cos} \varphi: 0,9$

3. Fasa-fasa

R-S : $417 \mathrm{~V}$
R-T : $414 \mathrm{~V}$
S-T : $420 \mathrm{~V}$

Hasil Pengukuran Pierching Connector dan Line Tap Connector

\section{Pengukuran Pierching Connector}

Analisa hasil pengukuran pierching connector pada T. 49 D1:

Tabel 1

Pengukuran input dan output pada pierching

connector

\begin{tabular}{|c|c|c|}
\hline Jenis Fasa & IN & OUT \\
\hline R-N & 235,8 V & 233,7 V \\
\hline S-N & 243,7 V & 241,6 V \\
\hline T-N & 235,7 V & 235,4 V \\
\hline
\end{tabular}

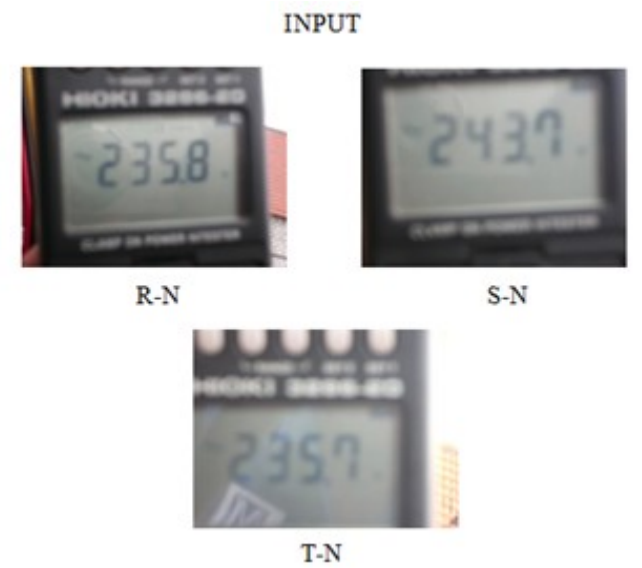

Gambar 4. Has il Pengukuran Pierching Connector Input

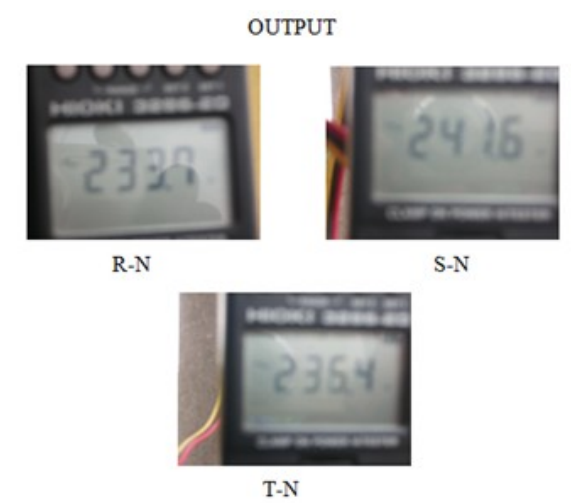

Gambar 5. Has il Pengukuran Pierching Connector Output

Pengukuran Line Tap Connector

Analisa hasil pengukuran line tap connector pada T. 49 D3 A1 :

Tabel 2

Pengukuran input dan output pada line tap

connector

\begin{tabular}{|c|c|c|}
\hline Jenis Fasa & IN & OUT \\
\hline R-N & $236,6 \mathrm{~V}$ & $236,6 \mathrm{~V}$ \\
\hline S-N & $\mathbf{2 4 0 , 7} \mathrm{V}$ & $\mathbf{2 4 0 , 7} \mathrm{V}$ \\
\hline T-N & $\mathbf{2 3 3 , 1} \mathrm{V}$ & $\mathbf{2 3 3 , 1} \mathrm{V}$ \\
\hline
\end{tabular}




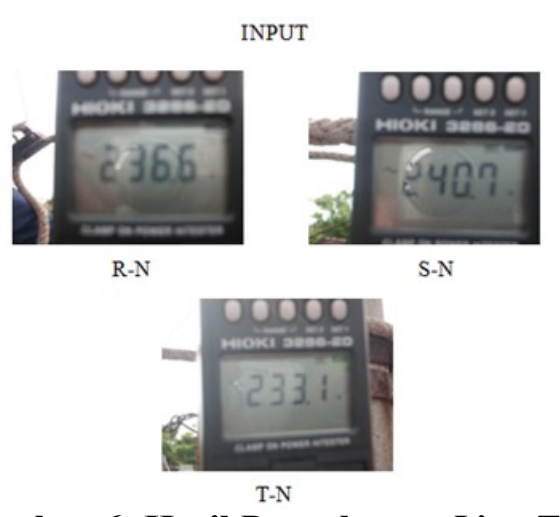

Gambar 6. Has il Pengukuran Line Tap Connector Input

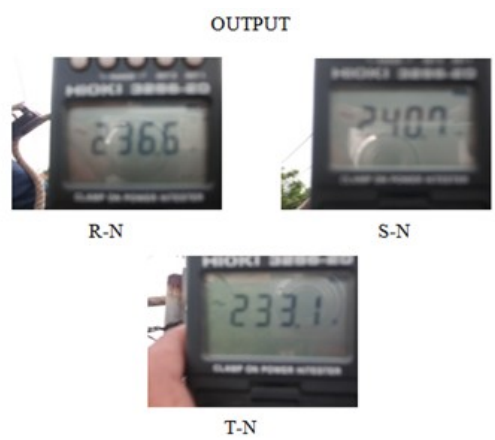

Gambar 7. Has il Pengukuran Line Tap Connector Output

Hasil perhitungan Rugi Daya

1. Perhitungan daya aktif dalam satuan watt. $P=V x I x \cos \varphi$

2. Perhitungan rugi daya dalam satuan watt.

$$
\mathrm{P}_{\text {rugi }}=\mathrm{P}_{\text {in }}-\mathrm{P}_{\text {out }}
$$

\section{T. 49 D1 (Pierching Connector)}

IN

$$
\begin{aligned}
& \text { R-N : } 235,8 \times 38,7 \times 0,9=8212,9 \quad \text { W } \\
& \text { S-N : } 243,7 \times 27,1 \times 0,9=5943,8 \quad W \\
& \mathrm{~T}-\mathrm{N}: 235,7 \times 49,7 \times 0,9=\frac{10542,9 \mathrm{~W}+}{24699,6 \mathrm{~W}}
\end{aligned}
$$

OUT

R-N : $233,8 \times 38,7 \times 0,9=8143,3 \quad$ W S-N : $241,6 \times 27,1 \times 0,9=5892,6 \quad \mathrm{~W}$ T-N : $235,4 \times 49,7 \times 0,9=\frac{10529,4 \quad W+}{24565,3 \quad W}$

$$
\mathrm{P}_{\text {rugi }}=\mathrm{P}_{\text {in }}-\mathrm{P}_{\text {out }}=24699,6-24565,3
$$$$
=134,3 \mathrm{~W}
$$

Selisih Rugi Daya adalah 134,3 W

\section{T. 49 D3 A1 (Line Tap Connector)}

IN

R-N : 236,6 × $38,7 \times 0,9=8240,8 \quad$ W

S-N : $240,7 \times 27,1 \times 0,9=5870,7 \quad W$

T-N : $233,1 \times 49,7 \times 0,9=\frac{10426,6 \quad W+}{24538,1} \mathrm{~W}$

OUT

R-N : 236,6 × $38,7 \times 0,9=8240,8 \quad$ W

S-N : $240,7 \times 27,1 \times 0,9=5870,7 \quad W$

$\mathrm{T}-\mathrm{N}: 233,1 \times 49,7 \times 0,9=\frac{10426,6 \quad \mathrm{~W}+}{24538,1 \mathrm{~W}}$

$$
\begin{gathered}
\mathrm{P}_{\text {rugi }}=\mathrm{P}_{\text {in }}-\mathrm{P}_{\text {out }}=24538,1-24538,1 \\
=0 \mathrm{~W}
\end{gathered}
$$

Selisih Rugi Daya adalah 0 W

Dari hasil analisa perhitungan rugi daya, terdapat hasil perhitungan antara input dan output pada tititk sambung pierching connector dan line tap connector:

T. 49 D1 (Pierching Connector) : 134,3 W

$$
\text { T. } 49 \text { D3 A1 (Line Tap Connector) : : } 0 \mathrm{~W}
$$

\section{Hasil Perhitungan Rugi Energi Daya Listrik} Dalam Satuan Rupiah

Dari hasil analisa rugi daya yang terjadi pada titik sambung pierching connector, maka dapat diketahui juga nilai nominal rugi energi daya listrik dalam hitungan satuan rupiah, berdasarkan tarif daya listrik (TDL) 2014 per $\mathrm{kWh}$ nya adalah Rp. 650,-:

$$
\mathrm{W}=\mathrm{P} \times \mathrm{t}
$$

\section{T. 49 D1 (Pierching Connector)}

Selis ih Rugi Daya : : $134,3 \mathrm{~W}$

Waktu :24 Jam

$$
\begin{aligned}
\mathrm{W} & =\mathrm{P} \times \mathrm{t} \times 30 \text { Hari } \\
& =134,3 \times 24 \times 30 \\
& =96696 \mathrm{Wh}
\end{aligned}
$$

$\mathrm{E} \quad=\frac{96696}{1000}=96,696 \mathrm{kWh}$

$\mathrm{Rp}=96,696 \times 650=62.852,-$

Jadi Rugi Energi Daya Listrik da lam satu bulan adalah Rp. 62.852,- Jika terjadi dalam satu tahun dalam hitungan waktu 24 jam adalah: $62.852 \mathrm{x}$ 12 Bulan $=754.224,-$ 


\section{Penyebab Rugi Daya Pada Penggunaan Pierching Connector}

Penyebab dari rugi daya pada pierching connector tersebut yaitu:

1. Dari segi pemasangan pierching connector yang tidak benar.

2. Pengencangan pada baut connector yang kurang kencang.

3. Peralatan pierching connector yang tidak standar PUIL PLN.

4. Kondisi pierching connector yang telah usang sehingga terjadi lost kontak di sambungan.

\section{Upaya PT. PLN (Persero) Untuk Menekan Terjadinya Rugi Daya}

Dari permasalahan diatas dan hasil wawancara penulis, bahwa untuk menekan terjadinya rugi daya pada pemasangan titik sambung pierching connector, PT. PLN (Persero) berupaya melakukan rekonektorisasi yaitu pergantian connector, dari connector sistem pierching connector diganti dengan line tap connector atau connector dengan sistem press. Manfaat dari rekonektor isasi adalah:

1. Menurunkan lossis atau penyusutan arus listrik untuk beberapa waktu.

2. Balanced beban listrik atau penyeimbang beban listrik yang terpakai.

3. Penyetabil arus listrik untuk beberapa waktu (non permanent).

4. Merapikan titik sambung antara JTR dan SR (non permanent).

5. Menghindari pencurian arus listrik.

\section{Kesimpulan}

\section{Penutup}

Dari hasil analisa data dan implementasi selama pelaksanaan Tugas Akhir maka penulis dapat memberikan kesimpulan sebagai berikut:

1. Hasil Perhitungan Rugi Daya

Dari hasil perhitungan analisa rugi daya, terdapat hasil perhitungan antara input dan output pada tititk sambung pierching connector dan line tap connector:

T. 49 D1 (Pierching Connector) : $134,3 \mathrm{~W}$

T. 49 D3 A1 (Line tap Connector) : $0 \mathrm{~W}$

2. Hasil Perhitungan Rugi Daya Dalam Satuan Rupiah
Dari hasil perhitungan analisa rugi daya, dapat diketahui kerugian daya pada titik sambung pierching connector dengan selisih nilai rugi daya 134,3 $\mathrm{W}$ dan jika dihitung da lam satuan rupiah, maka rugi energi daya listrik dalam satu bulan adalah Rp. 62.852,-. Jika terjadi dalam satu tahun dalam hitungan waktu 24 jam adalah $62.852 \times 12$ Bulan $=754.224$,-

\section{Penyebab Dari Rugi Daya Pada Pierching Connector}

Penyebab rugi daya pada titik sambung pierching connector yang terjadi pada T. 49 D1 adalah:

1) Dari segi pemasangan pierching connector yang tidak benar.

2) Pengencangan pada baut connector yang kurang kencang.

3) Peralatan pierching connector yang tidak standar PUIL PLN.

4) Kondisi pierching connector yang telah usang.

\section{DAFTAR PUSTAKA}

[1] Daman Suswanto, 2009. Sistem Distribusi Tenaga Listrik, Edisi Pertama. Padang: Lembaga Universitas Negeri Padang.

[2] Sugiyono. Prof. Dr, 2011. Metode Penelitian Kuantitatif Kualitatif dan R\&D, Edisi ke 13. Bandung: CV. Alfa Beta.

[3] Suhadi \& Tri Wrahatnolo, 2008. Teknik Distribusi Tenaga Listrik, Jilid I. Jakarta: PT. Macanan Jaya Cemerlang

[4]PT. PLN (PERSERO), 2010. Kontruksi Jaringan Distribusi Tenaga Listrik, Jilid I. Jakarta:PT. PLN (PERSERO) DISTRIBUSI.

[5] PT. PLN (PERSERO) Rayon Lamongan. Arsip dan Dokumentasi.

[6] Wahyudi Sarimun N. Ir. MT, 2011. Buku Saku Pelayanan Teknik (YANTEK), Edisi Kedua. Bekasi: Garamond.

[7] http:/e lektroumi.blogspot.com/2012/06/tegan gan-sistem-distribusi, diakses tanggal 15 Maret 2014.

[8] http $/ /$ indonetwork.co.id/cv aps/1182553/hiok i-3283-leak-clamp-tester.html, diakses tanggal 20 Maret 2014.

[9] http://repository.upi.edu/33/2/s-e52310811639-chapter1.pdf, diakses tanggal 15 Maret 2014. 